\title{
Minireview
}

\section{Role of insulin-like growth factor I receptor signalling in cancer}

\author{
O Larsson ${ }^{*, 1}$, A Girnita' and L Girnita' \\ 'Department of Oncology and Pathology, CCK R8:04, Karolinska Hospital, S-I 7176 Stockholm, Sweden
}

The insulin-like growth factor (IGF-I) signalling is highly implicated in cancer. In this signalling the IGF-I receptor (IGF-IR) is unquestionable, the predominating single factor. IGF-IR is crucial for tumour transformation and survival of malignant cell, but is only partially involved in normal cell growth. This is in part due to the interactions with oncogenes. Recent findings suggest a close interplay with the p53/MDM2 pathway. Disturbances in components in the p53/MDM2/IGF-IR network may cause IGF-IR upregulation and growth advantage for the cancer cell. Targeting of IGF-IR is more and more seen as a promising option for future cancer therapy. Single chain antibodies and small molecules with selective effects on IGF-IR dependent malignant growth are of particular interest. Forthcoming clinical trials are welcome and will indeed be the only way to evaluate the impact of IGF-IR targeting in human cancer. British Journal of Cancer (2005) 92, 2097-2 I0 I. doi:I0.I038/sj.bjc.6602627 www.bjcancer.com

Published online 24 May 2005

(c) 2005 Cancer Research UK

Keywords: IGF-I; IGF-I receptor; p53; MDM2; cancer

Mounting of evidence provided during the 10 last years implicates a crucial role of insulin-like growth factor 1 (IGF-1) signalling in development and progression of cancer. The most important single component in this signalling, involving the ligands IGF-1 and IGF-2, several binding proteins, proteases as well as three receptors, is the IGF-1 receptor (IGF-1R). In this review we will summarise relevant studies on the role of IGF-1R in cancer with focus on: (1) the unique role of IGF-1R signalling in malignant cells; (2) the interactions between IGF-1R and tumour suppressor genes and proto-oncogenes; as well as (3) current attempts in targeting the IGF-1R as a potential option in cancer therapy.

\section{UNIQUE ROLE OF IGF-1R IN CANCER}

The IGF-1R is a phylogenetically conserved receptor TK and belongs to the insulin receptor family, involving also the insulin receptor (IR), hybrid receptors and the IGF-2R/mannose 6phosphate receptor. The function of the hybrid receptor is still not well understood. The IGF-2R/6-mannose receptor is a monomeric receptor without TK activities. Both IGF-1R and IR are preformed dimeric TK receptors made up by two extracellular $\alpha$-subunits and two $\beta$-subunits involving a small extracellular domain, an intramembraneous one as well as an intracellular domain (Adams et al, 2000). The latter includes the juxtamembraneous domain, the TK domain and the C-terminal domain. The IGF-1R and IR are highly homologous, especially in the TK domain in which they share $84 \%$ amino-acid identities. However, despite these similarities, the functions between IGF-1R and IR differ considerably. The IGF-1R is mainly involved in regulation of cell proliferation, antiapoptosis, differentiation and cell motility, whereas IR is mostly of impact for control of glucose uptake and metabolism. However, the isoform A (exon 11-splice variant) of IR

*Correspondence: Dr O Larsson; E-mail: olle.larsson@onkpat.ki.se Received 21 January 2005; revised 19 April 2005; accepted 20 April 2005; published online 24 May 2005
(IR-A), normally expressed in fetal tissues, promotes cell growth in response to IGF-2 stimulation and has been reported to be abundantly expressed in some IGF-1R deficient leiomyosarcomas (Sciacca et al, 2002).

The ligand-receptor interaction results in phosphorylation of tyrosine residues in the IGF-1R TK domain (spanning amino acid 973-1229) of the $\beta$-subunit. The crystal structure of the inactive and phosphorylated kinase domain of the IGF-1R has provided a molecular model of the IGF-1R catalytic activity (Favelyukis et al, 2001). In unstimulated state, the activation loop (a-loop), containing the critical tyrosine $(\mathrm{Y})$ residues 1131,1135 and 1136 , behaves as a pseudosubstrate that blocks the active site. Y1135 (being the first tyrosine to be phosphorylated after stimulation with ligand) in the a-loop is bound in cis position in the active site, thus preventing the substrate access and occluding the ATP binding site as well. After ligand binding, the three tyrosines of the a-loop are transphosphorylated by the dimeric subunit partner. Phosphorylation of Y1135 and Y1131 destabilises the autoinhibitory conformation of the a-loop, whereas phosphorylation of Y1136 stabilises the catalytically optimised conformation of it (Favelyukis et al, 2001). These changes of the a-loop conformation allow the substrate and ATP access, further increasing the intrinsic TK activity towards phosphorylation of other tyrosines in the receptor and subsequently of exogenous substrate proteins. In turn, phosphorylation of the adaptor proteins insulin receptor substrate 1-4 (IRS-1-4) and Shc leads to activation of the phosphatidyl inositol-3 kinase (PI3K), the mitogen-activated protein kinase (MAPK) and the 14-3-3 pathways (Baserga, 2000).

In contrast to IR, IGF-1R is ubiquitously expressed in tissues in which it plays a role in tissue growth, mostly via the growth hormone, which liberates IGF-1 to activate the IGF-1R. Although this impact in normal growth, strong evidence has been provided that IGF-1R is not an absolute requirement for normal growth, only partially (Baserga, 1999).

On the other hand, IGF-1R has been shown to be crucial for anchorage independent growth, a property being well established to be unique for malignant cells. Classic experiments performed in Baserga's laboratory have demonstrated that anchorage 
dependency can be acquired when the number of IGF-1Rs at the cell surface is increased to certain amount (Baserga, 1999). The critical role of IGF-1R in anchorage independent growth has been confirmed in several other laboratories. This property of IGF-1R also implicates the function of this receptor in tumour progression since the degree of anchorage independency reflects the level of malignancy. This means that metastasis has acquired more anchorage independency, and more IGF-1R dependency, compared to the primary tumour.

Several studies, both experimental and clinical, have demonstrated that the IGF-1R is overexpressed compared to normal tissues (Belfiore et al, 1999; Xie et al, 1999; All-Ericsson et al, 2002). Furthermore, epidemiological prospective studies have identified high plasma levels of IGF-1 as a potential risk factor for several malignancies (Hankinson et al, 1998). In addition, IGF2 , whose expression normally is strictly controlled by parental imprinting is upregulated and functions as an important stimulant of the IGF-1R in cancer (LeRoith and Roberts, 2003). Thus, upregulation of IGF-1R and its ligands are probably important events for the malignant cell growth.

Another aspect on a unique role of IGF-1R in cancer is based on several recent findings that loss of suppressor oncogenes as well as activation of proto-oncogenes is related to IGF-1R function and activity (Baserga, 1994; Girnita et al, 2000; Werner and Le Roith, 2000; Werner et al, 2000; Girnita et al, 2003; Zhao et al, 2004). This area of research deserves a separate attention and is discussed in the next section of this review.

\section{Interactions between IGF-1R and oncogenes}

The IGF-1R gene is constitutively expressed in most cells. The promoter of IGF-1R is CG-rich and lacks TATA and CCAAT elements (LeRoith et al, 1995b), but has elements found in housekeeping genes, containing regulatory elements characteristic for highly regulated genes (Werner et al, 1991). The IGF-1R promoter exhibits a high basal transcriptional activity, and is under physiological control of nutritional factors (Olchovsky et al, 1993), hormonal stimulation (Clarke et al, 1997) and the developmental stage (Bondy et al, 1992). Its expression is altered in certain diseases, including cancer (LeRoith et al, 1995a; Baserga et al, 1997).

The IGF-1R promoter is targeted by several oncogenes. Constitutive overexpression of the proto-oncogenes c-myb in $\mathrm{Balb} / \mathrm{c}-3 \mathrm{~T} 3$ cells increases expression of both IGF-1 and IGF-1R, at least partly through an increased transcriptional activity and in this way abrogates the requirement for IGF-1 in the growing media (Kim et al, 1996). The hepatitis B virus $\mathrm{X}$ protein is another oncogene known to stimulate IGF-1R promoter activity (Kim et al, 1996) that may therewith play an aetiologic role in development of hepatocellular carcinoma. Some of the oncogenes increasing the IGF-1R promoter activity can also affect IGF-1R action by nontranscriptional mechanisms. For instance, transformation of human cells by the src oncogene of the Rous sarcoma virus results in constitutive phosphorylation of the receptor $\beta$-subunit, but addition of IGF-1 further increases the level of phosphorylation (Werner and Le Roith, 2000).

The IGF-1R gene contains several binding sites for members of $E R G$ family of transcription factors. Wilms' tumour 1 gene (WT1), a member of this family, is a tumour suppressor gene and its product has been shown to suppress the activity of promoters containing WT1 binding sites. Genes with WT1 targeting promoters include $I G F-1 R$ and $I G F-2$. WT1 has been shown to bind to the IGF-1R promoter and to suppress activity (Werner et al, 1995). Consistently, loss of WT1 activity in Wilms' tumour and related malignancies may result in transcriptional derepression of the IGF-1R gene (Gerald et al, 1995). Pathologic fusion of the Ewing gene EWS to WT1 $(\mathrm{t}(11 ; 22)(\mathrm{p} 13 ; \mathrm{q} 12)(E W S / W T 1))$ has been shown to abrogate the tumour suppressor function of WT1 and to generate an oncogenic chimeric protein capable of binding and activating the IGF-1R promoter (Karnieli et al, 1996).

Likewise, the suppressor oncogene p53 is capable of suppressing the activity of the IGF-1R promoter as well as lowering the endogenous levels of IGF-1R mRNA (Werner et al, 2000). In addition, the transcription of the IGF-2 gene is similarly reduced by wild-type p53 (Zhang et al, 1996). In contrast, tumour-derived, mutant versions of p53 significantly stimulated promoter activity (Werner et al, 1996). These data therefore suggest that upregulation of IGF-1R due to loss-of-function of p53 may facilitate selection of a malignant population of cells. However, the role of p53 in regulation of IGF-1R seems to be more complex and probably also involves post-transcriptional mechanisms (Girnita et al, 2000; Lee et al, 2003). This can be exemplified by malignant melanoma cells, most often harbouring wild-type p53 (Hussein, 2004), which exhibit overexpression of IGF-1R. Upon inhibition of wild-type p53 in these cells, they surprisingly responded with a drastic IGF-1R downregulation and cell death (Girnita et al, 2000). Similar results have been obtained in other studies (Lee et al, 2003). These observations points to the action of other mechanisms in the p53-dependent control of IGF-1R expression. Such a mechanism could theoretical be mediated by the oncoprotein MDM2, which interacts with p53 but has recently also been found to associate with certain cell surface receptors and regulate their functions (Shenoy et al, 2001). MDM2 is well known to strictly control p53. Overexpression of MDM2 results in decreased level and activity of p53 (Kubbutat et al, 1997) and provides an alternative to a 'p53 mutation' in the sense that it inactivates p53. In this way, MDM2 enables the development of tumours that retain wild-type p53. Just, recently, it was shown that under conditions when p53 was inhibited, MDM2 was redistributed and bound to the IGF-1R (Girnita et al, 2003). MDM2 was proven to ubiquitinate the IGF-1R and degraded it in a proteasome-dependent manner (Girnita et al, 2003), eventually leading to cell death. This action of MDM2 explains the earlier results that inhibition of wild-type p53 unexpectedly leads to downregulation of the IGF-1R (Girnita et al, 2000). These data are in consistent with several other studies reporting apoptotic effects due to overexpressed MDM2 (Vousden and Prives, 2005). However, drastic redistributions of MDM2 from p53 to the IGF-1R can probably only be achieved after experimental modulations, like inhibition of p53 expression by antisense strategies, etc, and do not likely occur in this manner in a physiologic context. On the other hand, an increased distribution of MDM2 to the cell nucleus to interact with p53 may indirectly increase the expression of IGF-1R since lesser cytoplasmic MDM2 will be available to ubiquitinate and degrade the receptor. Unpublished studies in our laboratory have suggested that some amounts of MDM2, by inducing ubiquitination, are important for internalisation and activation of the IGF-1R. However, if the MDM2 levels are becoming too abundant, the IGF-1R is overubiquitinated and degraded. These findings are also interesting from an IGF-1R targeting point of view because pharmacological modulations leading to an excess of MDM2 could be a manner to cause a selective IGF-1 inhibition and apoptosis in cancer cells.

Reciprocally, the IGF-1 system has been shown to influence the activity of MDM2. IGF-1 was demonstrated to regulate MDM2 activity by inhibiting the association between p19ARF and MDM2 in a p38 MAPK-dependent manner (Heron-Milhavet and LeRoith, 2002). Thus, when IGF1 was used to rescue the cells from UVinduced DNA damage, the p53 protein was degraded through the MDM2-mediated pathway. Others studies indicate that expression of phosphorylated Akt increases MDM2-mediated ubiquitination of p53 (Mayo and Donner, 2001). The serum-induced increase in p53 ubiquitination was blocked by a PI3K inhibitor, suggesting that phosphorylated Akt enhances the ubiquitination-promoting function of MDM2, determining reduction of the p53 protein.

In conclusion, there seems to exist a p53/MDM2/IGF-1R axis, in which signals are propagated in either direction. Changes leading 


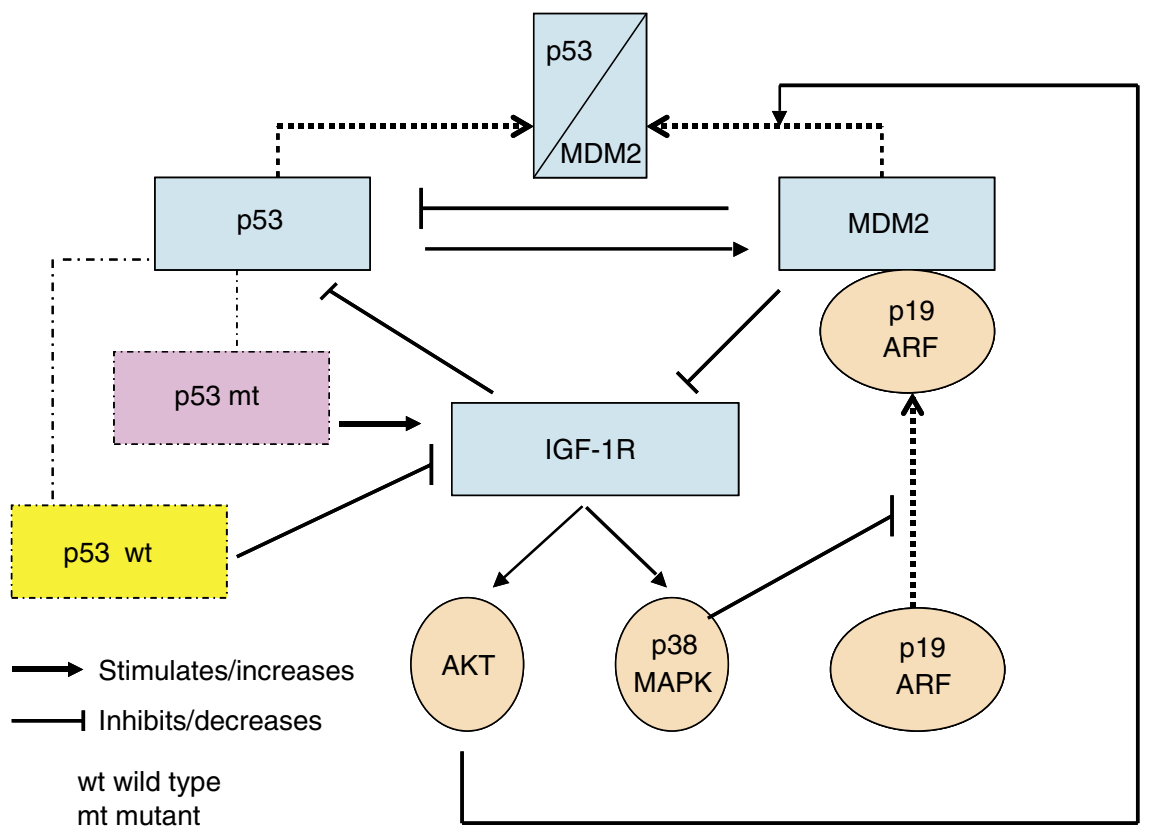

Figure I Interplay between p53, MDM2 and IGF-IR. The upper part of scheme shows that MDM2 can decrease p53 synthesis but also associate (indicated by dotted arrows) to it. This causes ubiquitination of p53. On the right it is indicated that p 9 ARF can associate (dotted arrow) to MDM2. This prevents MDM2 association to p53.

to increased distribution of MDM2 to the cell nucleus to inactivate p53 may contribute with a growth advantage for the tumour cells by upregulating the IGF-1R. This could be due to a derepressed transcription of the $I G F-1 R$ gene as well as a decreased ubiquitination and degradation of the receptor. A schematic picture illustrating possible links between p53 and IGF-1R is presented in Figure 1.

\section{TARGETING IGF-1R IN CANCER}

The vast expression of IGF-1R in neoplastic cells and tissues combined with its crucial roles in cancer cell growth is making this tyrosine receptor an attractive target to combat malignant diseases.

Blockade of IGF-1R has been convincingly shown to cause massive apoptosis of tumour cells in vivo, to inhibit tumorigenesis and block tumour invasion and metastasis. Overall, strategies leading to downregulation of the receptor, and not only inhibition of its TK activity, have been associated with the strongest antitumour efficacies (Baserga et al, 2003). This may be due to that a downregulation of IGF-1R is necessary to produce a complete inhibition of its function.

A variety of approaches aimed at targeting IGF-1R has been utilised to prove the concept, or are being developed for potential anticancer therapies. Targeting of IGF-1R to block its signalling may be obtained by interference with ligand/receptor interactions, receptor synthesis and expression, receptor TK activity, or combinations of these strategies.

Strategies aimed to block the ligand-receptor interaction involve receptor neutralising antibodies (Kalebic et al, 1994). Among those most studied is the monoclonal antibody $\alpha$-IR3, which competes with IGF-1 for binding to the receptor and blocks receptor activation (Van Wyk et al, 1985). However, $\alpha$ IR3 can sometimes act as an IGF1 mimetic and especially in cells overexpressing the IGF-1R (Kato et al, 1993). Antibody blockade of IGF-1R has been attempted in breast cancer model systems. However, the large size of the therapeutic molecule restricts its access to tumour cells, particularly in central regions of solid tumours (Russell et al, 1992). Smaller fragments are currently being studied as a substitute for whole antibodies in an effort to improve access and uptake. Sachdev et al (2003) used a singlechain antibody directed against IGF-1R (IGF-1R scFv-Fc) to examine the effects on IGF-1R signalling. In vivo treatment of mice bearing MCF-7 xenograft tumours with scFv-Fc resulted in near complete downregulation of IGF-1R.

Dominant-negative mutated IGF-1R (Dunn et al, 1998; Brodt et al, 2000) and truncated soluble IGF-1R (D'Ambrosio et al, 1996) are two related strategies to block IGF-1R. D'Ambrosio et al engineered by a frame-shift mutation a human IGF-1R cDNA that produces 486 amino acids long receptor. This truncated soluble receptor inhibited the autophosphorylation of the endogenous IGF-1R as well as induced extensive apoptosis in vivo and inhibited tumorigenesis in syngeneic rats. From a therapeutic point of view, these strategies suffer from the problem how to administrate these molecules to receive an efficient uptake in the tumour cells.

Antisense techniques are another way to inactivate the IGF-1R. Resnicoff et al (1994) used antisense RNA to IGF-1R by introducing it into cells by either addition of oligodeoxynucleotides or by transfection with plasmids expressing antisense RNA to IGF-1R RNA. Injection of glioblastoma cells (C6) IGF-1R antisense cells into rats carrying an established wild-type C6 tumour caused complete regression of the tumours. This fact further raises the possibility of practical applications targeting IGF-1R. Moreover, downregulation of IGF-1R, obtained by antisense strategies, has been reported to elicit a host response leading to eradication of surviving malignant cells in vivo (Resnicoff et al, 1996). Interestingly, in a pilot study, exposure of autologous glioma cells treated ex vivo with IGF-1R antisense oligos induced partial tumour regression in some patients with malignant astrocytoma (Andrews et al, 2001). This response seems to be immunogenic, involving the MHC I system, but is still not closer characterised.

A direct strategy to interfere with IGF-1R activity is to induce selective inhibition of its TK by developing selective smallmolecular inhibitors. The major advantage of this approach is that small molecules have a considerable higher bioavailability compared to antibodies, dominant-negative receptors and antisense oligonucleotides. However, TK inhibitors face the problem 
Table I Approaches to target IGF-IR

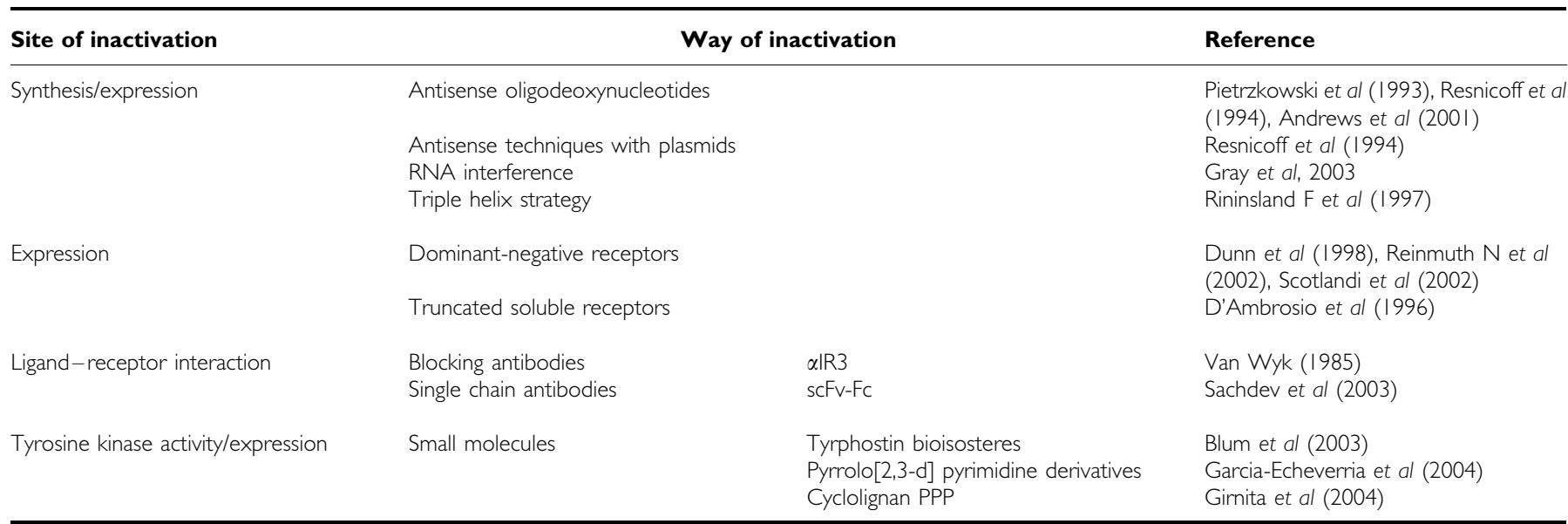

that IGF-1R and IR are so similar. Actually many of the hitherto developed IGF-1R TK inhibitors have also caused substantial inhibition of the IR. Such cross reaction would probably cause diabetic reactions in patients and can therefore not be accepted. On the other hand, IR-A dependent tumours would not be affected by a fully selective IGF-1R inhibitor.

Most of the IGF-1R TK inhibitors produced so far have served as competitive ATP inhibitors. Since the region of the TK domain covering the ATP binding site is identical to that of the IR, such cross-inhibitions are not unexpected. However, there is a recent interesting exception. Garcia-Echeverria et al (2004) presented a new compound (a pyrrolo[2,3-d] pyrimidine) that although inhibiting the IGF-1R and IR TK equipotently in cell-free systems, exhibited several-fold selectivity for the IGF-1R in a cellular context and reduced the growth of IGF-1R positive fibrosarcomas in vivo.

Blum et al (2003) presented a new family of bioisostere inhibitors, based on the structure of AG 538, a tyrphostin inhibiting the IGF-1R TK at the substrate level and not at the ATP binding site (Blum et al, 2000). These AG 538 bioisosteres possessed similar but weaker biological properties to AG 538 but are more stable and blocked the formation of colonies of prostate and breast cancer cells in soft agar systems (Blum et al, 2003).

Recently, we demonstrated that the cyclolignan PPP inhibited phosphorylation of IGF-1R without interfering with insulin receptor activity (Girnita et al, 2004), as well as it reduced phosphorylated Akt, caused apoptosis and induced tumour regression in xenografted mice. PPP did not compete with ATP but interfered with phosphorylation in the activation loop of the kinase domain, in which it specifically blocked phosphorylation of the tyrosine (Y) 1136 residue, while sparing the two others (Y1131 and Y1135). Since an IGF-1R construct, in which the tyrosine at position 1136 was replaced by a phenylalanine, also led to a strong inhibition of phosphorylated Akt in transfected cells, it was suggested that this mechanism may be responsible for the apoptotic effect of PPP (Vasilcanu et al, 2004). Unpublished studies have also demonstrated that the IGF-1Rs of PPP treated cells are undergoing rapid downregulation. This downregulation may be important for the strong apoptotic effect of this compound. Table 1 summarises different approaches to target the IGF-1R.

Although a huge number of experimental and preclinical investigations have provided encouraging results, clinical trials must be performed and completed to definitely evaluate the usefulness and risks of targeting IGF-1R as an option in cancer treatment of humans.

\section{ACKNOWLEDGEMENTS}

Own studies, cited in this review, were supported by grants from the Swedish Cancer Society, the Swedish Research Council, the Cancer Society in Stockholm, the Jubilee Fund of King Gustaf V, the Swedish Children Cancer Society and the Karolinska Institute.

\section{REFERENCES}

Adams TE, Epa VC, Garrett TP, Ward CW (2000) Structure and function of the type 1 insulin-like growth factor receptor. Cell Mol Life Sci 57: $1050-1093$

All-Ericsson C, Girnita L, Seregard S, Bartolazzi A, Jager MJ, Larsson O (2002) Insulin-like growth factor-1 receptor in uveal melanoma: a predictor for metastatic disease and a potential therapeutic target. Invest Ophthalmol Vis Sci 43: 1-8

Andrews DW, Resnicoff M, Flanders AE, Kenyon L, Curtis M, Merli G, Baserga R, Iliakis G, Aiken RD (2001) Results of a pilot study involving the use of an antisense oligodeoxynucleotide directed against the insulinlike growth factor type I receptor in malignant astrocytomas. J Clin Oncol 19: $2189-2200$

Baserga R (1994) Oncogenes and the strategy of growth factors. Cell 79: 927-930

Baserga R (1999) The IGF-I receptor in cancer research. Exp Cell Res 253: 1-6

Baserga R (2000) The contradictions of the insulin-like growth factor 1 receptor. Oncogene 19: $5574-5581$

Baserga R, Hongo A, Rubini M, Prisco M, Valentinis B (1997) The IGF-I receptor in cell growth, transformation and apoptosis. Biochim Biophys Acta 1332: F105-F126

Baserga R, Peruzzi F, Reiss K (2003) The IGF-1 receptor in cancer biology. Int J Cancer 107: 873-877

Belfiore A, Pandini G, Vella V, Squatrito S, Vigneri R (1999) Insulin/IGF-I hybrid receptors play a major role in IGF-I signaling in thyroid cancer. Biochimie 81: $403-407$

Blum G, Gazit A, Levitzki A (2000) Substrate competitive inhibitors of IGF1 receptor kinase. Biochemistry 39: $15705-15712$

Blum G, Gazit A, Levitzki A (2003) Development of new insulin-like growth factor-1 receptor kinase inhibitors using catechol mimics. J Biol Chem 278: $40442-40454$

British Journal of Cancer (2005) 92(|2), 2097-210| 
Bondy C, Werner H, Roberts Jr CT, LeRoith D (1992) Cellular pattern of type-I insulin-like growth factor receptor gene expression during maturation of the rat brain: comparison with insulin-like growth factors I and II. Neuroscience 46: 909-923

Brodt P, Samani A, Navab R (2000) Inhibition of the type I insulin-like growth factor receptor expression and signaling: novel strategies for antimetastatic therapy. Biochem Pharmacol 60: 1101-1107

Clarke RB, Howell A, Anderson E (1997) Type I insulin-like growth factor receptor gene expression in normal human breast tissue treated with oestrogen and progesterone. Br J Cancer 75: $251-257$

D’Ambrosio C, Ferber A, Resnicoff M, Baserga R (1996) A soluble insulinlike growth factor I receptor that induces apoptosis of tumor cells in vivo and inhibits tumorigenesis. Cancer Res 56: 4013-4020

Dunn SE, Ehrlich M, Sharp NJ, Reiss K, Solomon G, Hawkins R, Baserga R, Barrett JC (1998) A dominant negative mutant of the insulin-like growth factor-I receptor inhibits the adhesion, invasion, and metastasis of breast cancer. Cancer Res 58: $3353-3361$

Favelyukis S, Till JH, Hubbard SR, Miller WT (2001) Structure and autoregulation of the insulin-like growth factor 1 receptor kinase. Nat Struct Biol 8: $1058-1063$

Garcia-Echeverria C, Pearson MA, Marti A, Meyer T, Mestan J, Zimmermann J, Gao J, Brueggen J, Capraro HG, Cozens R, Evans DB, Fabbro D, Furet P, Porta DG, Liebetanz J, Martiny-Baron G, Ruetz S, Hofmann F (2004) In vivo antitumor activity of NVP-AEW541-A novel, potent, and selective inhibitor of the IGF-IR kinase. Cancer Cell 5: $231-239$

Gerald WL, Rosai J, Ladanyi M (1995) Characterization of the genomic breakpoint and chimeric transcripts in the EWS-WT1 gene fusion of desmoplastic small round cell tumor. Proc Natl Acad Sci USA 92: $1028-1032$

Girnita A, Girnita L, Prete Fd F, Bartolazzi A, Larsson O, Axelson M (2004) Cyclolignans as inhibitors of the insulin-like growth factor-1 receptor and malignant cell growth. Cancer Res 64: 236-242

Girnita L, Girnita A, Brodin B, Xie Y, Nilsson G, Dricu A, Lundeberg J, Wejde J, Bartolazzi A, Wiman KG, Larsson O (2000) Increased expression of insulin-like growth factor I receptor in malignant cells expressing aberrant p53: functional impact. Cancer Res 60: 5278-5283

Girnita L, Girnita A, Larsson O (2003) Mdm2-dependent ubiquitination and degradation of the insulin-like growth factor 1 receptor. Proc Natl Acad Sci USA 100: 8247-8252

Hankinson SE, Willett WC, Colditz GA, Hunter DJ, Michaud DS, Deroo B, Rosner B, Speizer FE, Pollak M (1998) Circulating concentrations of insulin-like growth factor-I and risk of breast cancer. Lancet 351: $1393-1396$

Heron-Milhavet L, LeRoith D (2002) Insulin-like growth factor I induces MDM2-dependent degradation of p53 via the p38 MAPK pathway in response to DNA damage. J Biol Chem 277: 15600-15606

Hussein MR (2004) The TP53 tumor suppressor gene and melanoma tumorigenesis: Is there a relationship? Tumor Biol 25: 200-207

Kalebic T, Tsokos M, Helman LJ (1994) In vivo treatment with antibody against IGF-1 receptor suppresses growth of human rhabdomyosarcoma and down-regulates p34cdc2. Cancer Res 54: $5531-5534$

Karnieli E, Werner H, Rauscher İII FJ, Benjamin LE, LeRoith D (1996) The IGF-I receptor gene promoter is a molecular target for the Ewing's sarcoma-Wilms' tumor 1 fusion protein. J Biol Chem 271: 19304-19309

Kato H, Faria TN, Stannard B, Roberts Jr CT, LeRoith D (1993) Role of tyrosine kinase activity in signal transduction by the insulin-like growth factor-I (IGF-I) receptor. Characterization of kinase-deficient IGF-I receptors and the action of an IGF-I-mimetic antibody (alpha IR-3). J Biol Chem 268: 2655-2661

Kim SO, Park JG, Lee YI (1996) Increased expression of the insulin-like growth factor I (IGF-I) receptor gene in hepatocellular carcinoma cell lines: implications of IGF-I receptor gene activation by hepatitis B virus $\mathrm{X}$ gene product. Cancer Res 56: $3831-3836$

Kubbutat MH, Jones SN, Vousden KH (1997) Regulation of p53 stability by Mdm2. Nature 387: 299-303

Lee YI, Han YJ, Lee SY, Park SK, Park YJ, Moon HB, Shin JH, Lee JH (2003) Activation of insulin-like growth factor II signaling by mutant type p53: physiological implications for potentiation of IGF-II signaling by p53 mutant 249. Mol Cell Endocrinol 203: 51-63

LeRoith D, Baserga R, Helman L, Roberts Jr CT (1995a) Insulin-like growth factors and cancer. Ann Intern Med 122: 54-59
LeRoith D, Roberts Jr CT (2003) The insulin-like growth factor systems and cancer. Cancer Lett 195: 127-137

LeRoith D, Werner H, Beitner-Johnson D, Roberts Jr CT (1995b) Molecular and cellular aspects of the insulin-like growth factor I receptor. Endocr Rev 16: $143-163$

Mayo LD, Donner DB (2001) A phosphatidylinositol 3-kinase/Akt pathway promotes translocation of $\mathrm{Mdm} 2$ from the cytoplasm to the nucleus. Proc Natl Acad Sci USA 98: 11598-11603

Olchovsky D, Song J, Gelato MC, Sherwood J, Spatola E, Bruno JF, Berelowitz M (1993) Pituitary and hypothalamic insulin-like growth factor-I (IGF-I) and IGF-I receptor expression in food-deprived rats. Mol Cell Endocrinol 93: $193-198$

Resnicoff M, Sell C, Rubini M, Coppola D, Ambrose D, Baserga R, Rubin R (1994) Rat glioblastoma cells expressing an antisense RNA to the insulin-like growth factor-1 (IGF-1) receptor are nontumorigenic and induce regression of wild-type tumors. Cancer Res 54: $2218-2222$

Resnicoff M, Tjuvajev J, Rotman HL, Abraham D, Curtis M, Aiken R, Baserga R (1996) Regression of C6 rat brain tumors by cells expressing an antisense insulin-like growth factor I receptor RNA. J Exp Ther Oncol 1: $385-389$

Russell SJ, Llewelyn MB, Hawkins RE (1992) Principles of antibody therapy. BMJ 305: $1424-1429$

Sachdev D, Li SL, Hartell JS, Fujita-Yamaguchi Y, Miller JS, Yee D (2003) A chimeric humanized single-chain antibody against the type I insulin-like growth factor (IGF) receptor renders breast cancer cells refractory to the mitogenic effects of IGF-I. Cancer Res 63: 627-635

Sciacca L, Mineo R, Pandini G, Murabito A, Vigneri R, Belfiore A (2002) In IGF-I receptor-deficient leiomyosarcoma cells autocrine IGF-II induces cell invasion and protection from apoptosis via the insulin receptor isoform A. Oncogene 21: $8240-8250$

Shenoy SK, McDonald PH, Kohout TA, Lefkowitz RJ (2001) Regulation of receptor fate by ubiquitination of activated beta 2 -adrenergic receptor and beta-arrestin. Science 294: 1307-1313

Van Wyk JJ, Graves DC, Casella SJ, Jacobs S (1985) Evidence from monoclonal antibody studies that insulin stimulates deoxyribonucleic acid synthesis through the type I somatomedin receptor. J Clin Endocrinol Metab 61: 639-643

Vasilcanu D, Girnita A, Girnita L, Vasilcanu R, Axelson M, Larsson O (2004) The cyclolignan PPP induces activation loop-specific inhibition of tyrosine phosphorylation of the insulin-like growth factor-1 receptor. Link to the phosphatidyl inositol-3 kinase/Akt apoptotic pathway. Oncogene 23: $7854-7862$

Vousden KH, Prives C (2005) P53 and prognosis; new insights and further complexity. Cell 120: 7-10

Werner H, Karnieli E, Rauscher FJ, LeRoith D (1996) Wild-type and mutant p53 differentially regulate transcription of the insulin-like growth factor I receptor gene. Proc Natl Acad Sci USA 93: 8318-8323

Werner H, Le Roith D (2000) New concepts in regulation and function of the insulin-like growth factors: implications for understanding normal growth and neoplasia. Cell Mol Life Sci 57: 932-942

Werner H, Shalita-Chesner M, Abramovitch S, Idelman G, ShaharabaniGargir L, Glaser T (2000) Regulation of the insulin-like growth factor-I receptor gene by oncogenes and antioncogenes: implications in human cancer. Mol Genet Metab 71: 315-320

Werner H, Shen-Orr Z, Rauscher III FJ, Morris JF, Roberts Jr CT, LeRoith D (1995) Inhibition of cellular proliferation by the Wilms' tumor suppressor WT1 is associated with suppression of insulin-like growth factor I receptor gene expression. Mol Cell Biol 15: 3516-3522

Werner H, Stannard B, Bach MA, Roberts Jr CT, LeRoith D (1991) Regulation of insulin-like growth factor I receptor gene expression in normal and pathological states. Adv Exp Med Biol 293: 263-272

Xie Y, Skytting B, Nilsson G, Brodin B, Larsson O (1999) Expression of insulin-like growth factor-1 receptor in synovial sarcoma: association with an aggressive phenotype. Cancer Res 59: 3588-3591

Zhang L, Kashanchi F, Zhan Q, Zhan S, Brady JN, Fornace AJ, Seth P, Helman LJ (1996) Regulation of insulin-like growth factor II P3 promotor by p53: a potential mechanism for tumorigenesis. Cancer Res 56: $1367-1373$

Zhao H, Dupont J, Yakar S, Karas M, LeRoith D (2004) PTEN inhibits cell proliferation and induces apoptosis by downregulating cell surface IGFIR expression in prostate cancer cells. Oncogene 23: 786-794 